\title{
Bismuth catalyst mediated degradation of $p$-hydroxyphenylacetic acid: Photoactivation, interfacial mechanism, and influence of some critical parameters
}

Xiaoning Wang ${ }^{\mathrm{a}, \mathrm{b}}$, Marcello Brigante ${ }^{\mathrm{a}}$, Gilles Mailhot ${ }^{\mathrm{a}_{*}}$, Wenbo Dong ${ }^{\mathrm{b}}$

a Université Clermont Auvergne, CNRS, SIGMA Clermont, Institut de Chimie de Clermont-Ferrand, F-63000 Clermont-Ferrand, France.

${ }^{\mathrm{b}}$ Shanghai Key Laboratory of Atmospheric Particle Pollution and Prevention, Department of Environmental Science \& Engineering, Fudan University, Shanghai 200433, China

* Corresponding Authors: Wenbo Dong (wbdong@fudan.edu.cn) and Gilles Mailhot (gilles.mailhot@uca.fr)

\section{Keywords}

Remediation, treatment, superoxide radical, mineralization, photocatalysis 


\section{Abstract}

The adsorption and photocatalytic degradation abilities of bismuth catalyst $\left(\mathrm{BiOCl}_{0.75} \mathrm{I}_{0.25}\right)$ in water are tested under simulated solar light by using p-hydroxyphenylacetic acid ( $p$-HPA) as chemical pollutant. On the basis of the strong adsorption of $p$-HPA on the catalyst surface, this work aims to investigate the interfacial mechanism in the heterogeneous system through adsorption/desorption experiments by using competitive-anion desorption with phosphate anions. The key factors affecting the degradation kinetics of $p$-HPA such as $\mathrm{pH}$ and dissolved oxygen concentration are investigated. We find that solution $\mathrm{pH}$ significantly affects the adsorption and degradation rates depending on the zeta potential of catalyst and molecular form of $p$-HPA. $p$-HPA shows maximum adsorption at $\mathrm{pH} 4.5$ and faster degradation rate at $\mathrm{pH}$ 3.0. Dissolved oxygen concentration is a key factor affecting pollutant removal because of the formation of hydroperoxide/superoxide radical anion couple $\left(\mathrm{HO}_{2}{ }^{\bullet} / \mathrm{O}_{2}{ }^{\bullet-}\right)$. These radicals, which are the main reactive species involved in the reaction after irradiation of catalyst, are detected using competition-kinetics approach and selective radical probes.

Keywords: photocatalytic degradation, adsorption, interfacial reactivity, hydroperoxide/superoxide radical anion. 


\section{Introduction}

In recent years, advanced oxidation processes (AOPs) have been proposed as alternative methods to the removal of persistent organic pollutants in different environmental media [1-3]. Generally, AOPs can achieve recalcitrant pollutant destruction when biological treatments for endocrine disrupting chemicals $[4,5]$, pharmaceuticals, and personal care products $[6,7]$ are unfeasible. Main oxidation processes are usually performed based on the in situ production of highly reactive species such as hydroxyl $(\mathrm{HO} \bullet)$ and sulfate radical $\left(\mathrm{SO}_{4}{ }^{\bullet-}\right)$, which can oxidize organic pollutants in aqueous solutions $[1,2]$. In the last two decades, different AOPs on the basis of iron activation under the dark [8, 9], UV light [10], and/or in the presence of radical precursors [11] have been proposed, demonstrating their efficiency for organic pollutant reduction. Heterogeneous semiconductor photocatalysis is also one of the most promising oxidation processes. Under irradiation, electron $\left(\mathrm{e}^{-}\right)$and hole $(\mathrm{h}+)$ pairs can be produced in conduction and valence bands, leading to the formation of reactive oxygen species (ROS) such as $\mathrm{HO}^{\bullet}$ or $\mathrm{HO}_{2}{ }^{\bullet} / \mathrm{O}_{2}{ }^{\bullet-}\left(\mathrm{pK}_{\mathrm{a}}=4.88\right)$ [12]. Among different photocatalysts, $\mathrm{TiO}_{2}$ and modified $\mathrm{TiO}_{2}$ materials have received considerable attention due to their chemical stability and high efficiency under UV light degradation of pollutants present in gas and liquid phases [13-17]. Subsequently, photocatalytic properties of new materials such as hierarchical bismuth-related catalyst especially $\mathrm{BiOX}(\mathrm{X}=\mathrm{Cl}, \mathrm{Br}, \mathrm{I})$, have been investigated [18, 19]. $\mathrm{BiOX}$ has internal structure of $\mathrm{Bi}_{2} \mathrm{O}_{2}$ layers interleaved by double slabs of $\mathrm{X}^{-}$atoms, which 
provide a sufficient space to polarize related atoms and orbitals, facilitating the separation of electrons and holes [20]. BiOX particles have tunable activation wavelength and oxidation abilities with different band gaps. Thus, composite catalysts such as $\mathrm{BiOCl} / \mathrm{BiOI}$ or $\mathrm{BiOBr} / \mathrm{BiOI}$ can optimize the advantages of these photocatalysts, showing potential degradation abilities on various pollutants [20-23].

Pharmaceuticals in water have emerged as one of the most urgent issues due to their massive use and potential chronic health effects [24, 25]. Pharmaceutically active compounds have been detected in sewage treatment plants, surface water, and even in drinking water at a concentration of $n g$ to $\mu \mathrm{g}$ per $\mathrm{L}[5,26]$.

In this study, $p$-hydroxyphenylacetic acid ( $p$-HPA), which is one of pharmaceutical compound and pesticide intermediates that are widely detected in olive oil extraction and wine distillery processes, is chosen as the model pollutant. $p$-HPA is a priority phenolic pollutant present in wastewaters from some agroindustrial plants [27]. In the last two decades, the removal of $p$-HPA by using $\mathrm{UV} / \mathrm{H}_{2} \mathrm{O}_{2}$, Fenton [27], pyrylium salt-photosensitized degradation [28], zero-valence iron catalytic degradation [29], electrochemical reaction [30, 31], and catalytic wet air processes [32] have been investigated.

In this paper, $\mathrm{BiOCl}_{0.75} \mathrm{I}_{0.25}$ is used to remove $p$-HPA in solution. Particular attention is given to the interfacial mechanisms and role of adsorption on the photoinduced $p$-HPA degradation in the presence of catalyst. Moreover, the effect of solution $\mathrm{pH}$ and dissolved oxygen are elucidated using chemical-competition 
approach.

\section{Materials and methods}

\subsection{Chemicals}

$\mathrm{BiOCl}_{0.75} \mathrm{I}_{0.25}$ catalyst was synthesized following the previously reported procedure [23] and was stored in the dark before use. p-HPA, potassium iodide (KI), 1,4-benzoquinone (BQ), isoproponal (IPA), and Sodium dihydrogen phosphate $\left(\mathrm{NaH}_{2} \mathrm{PO}_{4}\right)$ were obtained from Sigma-Aldrich, France. $\mathrm{HClO}_{4}$, and $\mathrm{NaOH}$ were used to adjust the solution $\mathrm{pH}$. All chemicals were used without further purification, and milli-Q water was used to prepare solution.

\subsection{Irradiation setup and experimental procedure}

Photocatalytic degradation experiments were performed in a homemade photoreactor placed in a cylindrical stainless steel container. Four fluorescent light bulb lamps (Philips TL D15W/05) were separately placed in four different axes. Meanwhile, the photoreactor, which is a water-jacketed Pyrex tube with $2.8 \mathrm{~cm}$ internal diameter, was placed at the center of the setup. Irradiation with the predominant wavelength between $300 \mathrm{~nm}$ to $500 \mathrm{~nm}$ was used to simulate solar light. The emission spectrum (Figure S1) reaching the solution was determined using an optical fiber coupled with a CCD spectrophotometer (Ocean Optics USD 
2000+UV-VIS) calibrated using a DH-2000-CAL Deuterium Tungsten Halogen Reference Lamp. Energy has been normalized to actinometry results by using paranitroanisole/pyridine actinometer [33]. At the wavelength range of 300-500 nm, a total flux of $1451 \mathrm{~W} \mathrm{~m}^{-2}$ reaching the solution was determined.

Solutions were magnetically stirred with a magnetic bar during irradiation, and the total volume of the solution was $100 \mathrm{~mL}$. $p$-HPA adsorption on bismuth catalyst was investigated in the dark with continuous magnetic stirring. All experiments were carried out at room temperature $(293 \pm 2 \mathrm{~K})$ by using a circulating cooling water system. An aliquot of solution $(1 \mathrm{~mL})$ was withdrawn from the reactor at fixed interval times. In addition, the catalyst solid was removed by $0.2 \mu \mathrm{m}$ PTFE filters before analysis. Prior to the use of PTFE filter, control experiments were performed, showing that no adsorption of $p$-HPA was observed on these filters. Experiments were performed using $p$-HPA at $50 \mu \mathrm{M}$ and $\mathrm{BiOCl}_{0.75} \mathrm{I}_{0.25}$ catalyst at $0.3 \mathrm{~g} \mathrm{~L}^{-1}$. The effect of dissolved oxygen on $p$-HPA degradation and radical species involvement were carried out by bubbling $\mathrm{N}_{2}$ or $\mathrm{O}_{2}$ for 20 min before catalyst addition and all throughout the experiment with and without light.

\subsection{Analytical procedure}

The concentration of remaining $p$-HPA in the aqueous solution was determined by an alliance high-performance liquid chromatography (HPLC) equipped with a photodiode array detector (Waters 2998, USA) and Waters 2695 Separations Module. 
The flow rate was $0.15 \mathrm{~mL} \mathrm{~min}{ }^{-1}$, the injection volume was $50 \mu \mathrm{L}$, and the mobile phase was a mixture of water with $0.1 \% \mathrm{H}_{3} \mathrm{PO}_{4}$ and methanol $(65 / 35$, v/v). The column was a Nucleodur $100-3 \mathrm{C} 18$ of $150 \times 2.0 \mathrm{~mm}$, with particle size of $3 \mu \mathrm{m}$. Under these conditions, $p$-HPA was detected at $274 \mathrm{~nm}$, and retention time was 6.7 min. BQ concentration was determined by HPLC-UV by using the same column and mobile phase with a detection wavelength set at $245 \mathrm{~nm}$. The retention time of BQ was $4.9 \mathrm{~min}$.

UV-visible (UV-vis) spectra were recorded with a Cary 300 UV-vis spectrophotometer. The $\mathrm{pH}$ values of the solutions were measured using a CyberScan $510 \mathrm{pH}$ meter. Mineralization of $p$-HPA solution was determined by total organic carbon (TOC) analysis (5050A, Shimadzu, Japan). The limit of detection and limit of quantification have been determined to be 17 and $50 \mu \mathrm{gC} \mathrm{L}^{-1}$, respectively, considering the signal-to-noise ratio.

During $\mathrm{BiOCl}_{0.75} \mathrm{I}_{0.25}$ photocatalytic degradation process under simulated solar light, the transformation products of $p$-HPA were detected by GC-MS (7890A/5975C, Agilent, USA). Products were extracted from the aqueous solution with $\mathrm{CH}_{2} \mathrm{Cl}_{2}$ by solid-phase extraction. GC-MS was equipped with a HP-5MS polysiloxane polymer column $(30 \mathrm{~m} \times 0.25 \mathrm{~mm} \times 0.25 \mu \mathrm{m})$ with helium as the carrier gas at a flow rate of $1.0 \mathrm{~mL} \mathrm{~min}{ }^{-1}$. The column temperature was set at $100{ }^{\circ} \mathrm{C}$, held for $2 \mathrm{~min}$, and increased at a rate of $15{ }^{\circ} \mathrm{C} / \mathrm{min}$ until it reached $300{ }^{\circ} \mathrm{C}$. The injector and interface temperature were both set at $280^{\circ} \mathrm{C}$. An electron impact ionization was used for MS 
measurement in full scan mode ( $\mathrm{m} / \mathrm{z}=50$ to 600$)$. Moreover, the MS source settings are as follows: ionization voltage, $70 \mathrm{eV}$; electron multiplier voltage, $1 \mathrm{kV}$; source temperature, $230{ }^{\circ} \mathrm{C}$; quadruple temperature, $150{ }^{\circ} \mathrm{C}$; and vacuum degree, $6.0 \times 10^{-6}$ Torr.

Total $p$-HPA was determined as the sum of $p$-HPA present in the aqueous solution and adsorbed on the catalyst surface, which was determined after desorption experiments. Desorption of $p$-HPA was performed by adding $500 \mu \mathrm{L}$ of $2 \mathrm{mM}$ sodium dihydrogen phosphate solution to $500 \mu \mathrm{L}$ of the sample. Solution was filtered after 5 min to remove the catalyst particles and was analyzed by HPLC-UV.

\subsection{Catalyst characterization}

X-ray photoelectron spectroscopy (XPS) spectra were recorded with a PerkinElmer PHI 5000C ESCA system equipped with a hemispherical electron energy analyzer. The $\mathrm{Mg} \mathrm{Ka}(\mathrm{h} v=1253.6 \mathrm{eV})$ anode was operated at $14 \mathrm{kV}$ and $20 \mathrm{~mA}$. The carbonaceous $\mathrm{C}$ 1s line $(284.6 \mathrm{eV})$ was used as the reference to calibrate the binding energies (BEs). The UV-vis diffuse reflection spectra (DRS) were obtained for the samples using a Scan UV-vis spectrophotometer (Thermo Nicolet Evolution 500 UV-vis) equipped with an integrating sphere assembly, and $\mathrm{BaSO}_{4}$ was used as reflectance sample. 


\section{Results and discussion}

\subsection{Physicochemical properties of BiOCl $\mathrm{B}_{0.75} \mathrm{I}_{0.25}$ catalyst}

The physicochemical properties of $\mathrm{BiOCl}_{0.75} \mathrm{I}_{0.25}$ catalyst are summarized in Table S1. Catalyst is synthesized through a precipitation method in ambient pressure, following the procedure reported in a previous work [23]. The $\mathrm{BiOCl}_{0.75} \mathrm{I}_{0.25}$ crystals show flower-like morphology with larger surface area and higher total pore volume than those of BiOX catalyst [21, 34]. These results facilitated the adsorption of $p$-HPA molecules on the surface and the supply of abundant active sites for oxidation ability. Introduction of I onto the $\mathrm{BiOCl}$ crystalline lattices induces the formation of heterojunction and decreases the recombination rate of hole-electron pairs. By contrast to $\mathrm{BiOCl}$ alone, the band gap of $\mathrm{BiOCl}_{0.75} \mathrm{I}_{0.25}$ is adjusted to $2.12 \mathrm{eV}$, which is suitable for the utilization of simulated solar light $(\lambda>300 \mathrm{~nm})$ (Figure S2). To further investigate the surface chemical compositions of $\mathrm{BiOCl}_{0.75} \mathrm{I}_{0.25}$ samples, we conducted XPS studies, and the spectra are illustrated in Fig. 1. As shown in Fig. 1A, the sample is composed of $\mathrm{C}, \mathrm{Bi}, \mathrm{O}, \mathrm{Cl}$, and $\mathrm{I}$ atoms. Their corresponding high-resolution XPS spectra are shown in Figs. 1B-F, respectively. Fig. 1B displayed the $\mathrm{C}$ peak fixed at 284.6 and $281.39 \mathrm{eV}$, which can be attributed to the adventitious $\mathrm{C}$ on the sample surface from the solvent and XPS instrument [34, 35]. Fig. 1C shows that two strong peaks with BEs of 164.42 and $159.11 \mathrm{eV}$ correspond to $\mathrm{Bi} 4 \mathrm{f}_{5 / 2}$ and $\mathrm{Bi}$ $4 f_{7 / 2}$, indicating that the main chemical state of $\mathrm{Bi}$ element is trivalent [36]. The $\mathrm{O} 1 \mathrm{~s}$ spectrum is shown in Fig. 1D, which can be fitted by three peaks at the BEs of 530.61, 
531.85 , and $532.83 \mathrm{eV}$. The peak at $530.61 \mathrm{eV}$ is characteristic of $\mathrm{Bi}-\mathrm{O}$ binding energy, and the two remaining peaks with higher BEs than the first peak can be assigned to adsorbed $\mathrm{H}_{2} \mathrm{O}$ or surface hydroxyl groups on the surface of sample [37]. $\mathrm{Cl} 2 \mathrm{p}_{3 / 2}$ and $\mathrm{Cl} 2 \mathrm{p}_{1 / 2}$ peaks at 197.95 and $199.6 \mathrm{eV}$ BEs indicate that the valance state of chlorine element is -1 in the sample (Fig. 1E) [38]. As shown in Fig. 1F, the I $3 d$ peaks are divided into two peaks at approximately 630.63 and $619.21 \mathrm{eV}$, corresponding to I $3 \mathrm{~d}_{3 / 2}$ and $\mathrm{I} 3 \mathrm{~d}_{5 / 2}$, respectively. This result indicates that the valance state of $\mathrm{I}$ is -1 [38]. Therefore, we can argue that $\mathrm{BiOCl}_{0.75} \mathrm{I}_{0.25}$ sample is well constructed with correct chemical composition and valance state.

\subsection{Generation of reactive species}

Reactive species generated under $\mathrm{BiOCl}_{0.75} \mathrm{I}_{0.25}$ catalyst irradiation were determined using competition-kinetics approach with specific scavengers in the solution. IPA, KI, and BQ are taken as $\mathrm{HO}^{\bullet}\left(k_{I P A, H O^{\bullet}}=1.9 \times 10^{9} \mathrm{M}^{-1} \mathrm{~s}^{-1}\right)[39], \mathrm{h}^{+}[40]$, and $\mathrm{HO}_{2}{ }^{\bullet} / \mathrm{O}_{2}^{\bullet-}\left(k_{B Q, O_{2}^{-}}=9.0 \times 10^{8} \mathrm{M}^{-1} \mathrm{~s}^{-1}\right)$ [41] scavengers, respectively. The addition of $1 \mathrm{mM}$ IPA by using $0.3 \mathrm{~g} \mathrm{~L}^{-1}$ of catalyst do not modify the degradation rate of p-HPA under irradiation at $\mathrm{pH} 3.0$ (Fig. S3), indicating that $\mathrm{HO}^{\bullet}$ is not generated during irradiation of $\mathrm{BiOCl}_{0.75} \mathrm{I}_{0.25}$ catalyst. The effect of $\mathrm{KI}$ addition was investigated at $\mathrm{pH} 4.5$ due to the anion exchange with $\mathrm{Cl}^{-}$and consequent modification of catalyst occurring at $\mathrm{pH} 3.0$ [42]. The presence of $1 \mathrm{mM}$ of KI (Fig.S4) strongly inhibits the adsorption of $p$-HPA due to the electrolyte changed surface charge of $\mathrm{BiOCl}_{0.75} \mathrm{I}_{0.25}$ 
catalyst. As a matter of fact, if we compare the concentration of remaining $p$-HPA in the solution in the presence and absence of KI (85\% and 58\%, respectively, as shown in Fig S4), then we can argue that the difference (approximately 27\%) corresponds to the $p$-HPA adsorbed on the catalyst surface after $60 \mathrm{~min}$ in the dark. Under irradiation, a similar value for the pseudo-first-order kinetic constant of $p$-HPA degradation $\left(k_{\text {app }}\right)$ is determined without and with $\mathrm{KI}\left(0.020\right.$ and $0.019 \mathrm{~min}^{-1}$, respectively), indicating that the valance band holes are not the main active species responsible for $p$-HPA removal. When $1 \mathrm{mM}$ of $\mathrm{BQ}\left(\mathrm{HO}_{2}{ }^{\bullet} / \mathrm{O}_{2}^{\bullet-}\right.$ scavenger $)$ is added in the solution, $p$-HPA adsorption (first $60 \mathrm{~min}$ ) is not modified. However, no degradation is observed under irradiation (Fig. 2). This experiment indicates that the generated $\mathrm{HO}_{2}{ }^{\bullet} / \mathrm{O}_{2}{ }^{\bullet-}\left(\mathrm{pK}_{\mathrm{a}}=\right.$ 4.88) under catalyst irradiation drives the $p$-HPA degradation, which is in agreement with the results of previously reported works [23]. To further investigate the degradation mechanism and catalyst surface implication, we followed the concentration of $\mathrm{BQ}$ during the adsorption and photodegradation steps (Fig. S5). Although no adsorption is observed for the first $60 \mathrm{~min}$ in the dark, BQ disappears under irradiation, indicating the formation of $\mathrm{HO}_{2}{ }^{\bullet} / \mathrm{O}_{2}{ }^{\bullet-}$ species in the solution.

\subsection{Effects of $p H$ on $p$-HPA adsorption and photocatalytic degradation}

p-HPA adsorption on the catalyst surface and photocatalytic degradation in aqueous solution were investigated at different $\mathrm{pH}$ values (Fig. 3). The adsorption of p-HPA is strongly related to the molecular form of $p$-HPA $\left(\mathrm{pK}_{\mathrm{a} 1}=4.5\right.$ and $\mathrm{pK}_{\mathrm{a} 2}=$ 
10.5) and the surface zeta potential of $\mathrm{BiOCl}_{0.75} \mathrm{I}_{0.25}$ catalyst [43].

Moreover, the zeta potential of $\mathrm{BiOCl}_{0.75} \mathrm{I}_{0.25}$ was tested as a function of $\mathrm{pH}$, as shown in Fig. S6. As shown in this figure, the point of zero charge of $\mathrm{BiOCl}_{0.75} \mathrm{I}_{0.25}$ is located at approximately $\mathrm{pH} 1.6$, indicating that within our experimental $\mathrm{pH}$ range, the zeta potential of $\mathrm{BiOCl}_{0.75} \mathrm{I}_{0.25}$ is always negative. K. Li et al. [44] and G. Li et al. [45] obtained similar results in their studies. This result indicates that in solutions, electrostatic attraction occurs between the positively charged $p$-HPA and negatively charged $\mathrm{BiOCl}_{0.75} \mathrm{I}_{0.25}$, inducing a strong adsorption of $p$-HPA on the catalyst surface [46]. Similar trend is observed for Rhodamine B, which has one carboxyl group [46, 47]. Table 1 summarizes the pseudo-first-order decay of $p$-HPA at different $\mathrm{pH}$ values, as well as zeta potential of $\mathrm{BiOCl}_{0.75} \mathrm{I}_{0.25}$. At $\mathrm{pH} 3.0, p$-HPA is in molecular form, and the zeta potential of $\mathrm{BiOCl}_{0.75} \mathrm{I}_{0.25}$ is $-8 \mathrm{mV}$. Thus, when the solution $\mathrm{pH}$ decreases at 3.0, the $\mathrm{H}_{3} \mathrm{O}^{+}$ions compete with $p$-HPA molecules to the adsorption onto the negatively charged catalyst surface. At natural $\mathrm{pH}$ (4.5), p-HPA is 50\% under molecular and anionic forms, and adsorption is not modified by the presence of other external ions. The zeta potential of $\mathrm{BiOCl}_{0.75} \mathrm{I}_{0.25}$ at $\mathrm{pH} 4.5$ is more negative compared with the zeta potential at $\mathrm{pH}$ 3.0. Moreover, $p$-HPA adsorption is higher showing at $80 \%$ remaining in the solution after $1 \mathrm{~h}$ in the dark at $\mathrm{pH} 3.0$ than at $60 \%$ at the $\mathrm{pH} 4.5$. With increased $\mathrm{pH}$ to 7.5 and $9.5, p$-HPA is under anionic form, the zeta potential of $\mathrm{BiOCl}_{0.75} \mathrm{I}_{0.25}$ is more negative with value lower than $-38 \mathrm{mV}$. At $\mathrm{pH} 7.5$ and 9.5 , the more negative surface charge causes electrostatic repulsion, so p-HPA adsorption 
decreases. As shown in Fig. 3, fast degradation is observed at pH 3.0 under irradiation, consistent with previously reported results. Thus, under acidic solutions, pollutant photodegradation in aqueous solution by BiOX catalyst is also faster [48, 49]. Two main factors can induce this result; one is the different forms of main active species $\mathrm{HO}_{2}{ }^{\bullet} / \mathrm{O}_{2}{ }^{\bullet-}\left(\mathrm{pK}_{\mathrm{a}}=4.88\right)$, and the other one is the form of $p$-HPA $\left(\mathrm{pK}_{\mathrm{a}}=4.5\right)$ present in the solution, both of which are closely related to $\mathrm{pH}$. Furthermore, more negative charged surface will restrict the migration of electrons to the surface of catalyst and formation of superoxide radicals. Thus, combined with the conclusion in our previous studies [23], we can argue that $p$-HPA has higher reactivity with radicals $\mathrm{HO}_{2}^{\bullet}$ under its molecular form than with $\mathrm{O}_{2}^{\bullet-}$.

\subsection{Interfacial mechanism under irradiation}

To investigate the role of catalyst surface on the $p$-HPA degradation under irradiation, we performed different experiments in the presence of $\mathrm{H}_{2} \mathrm{PO}_{4}{ }^{-}$, which can compete with $p$-HPA for adsorption on the catalyst surface. In the presence of $2 \mathrm{mM}$ $\mathrm{H}_{2} \mathrm{PO}_{4}{ }^{-}$in solution, relatively no adsorption of $p$-HPA is observed in the dark for $1 \mathrm{~h}$. Moreover, degradation under irradiation is strongly inhibited (Fig. 4A). This effect suggests that $p$-HPA degradation occurs mainly on the catalyst surface. Experiments to assess the role of catalyst surface on the possible adsorption of $p$-HPA are shown in Fig. 4B, in which BQ that was used as $\mathrm{HO}_{2}{ }^{\bullet} / \mathrm{O}_{2}{ }^{\bullet-}$ scavenger was added in the solution. BQ does not affect the $p$-HPA adsorption on the catalyst surface. As a matter of fact, 
for the first $30 \mathrm{~min}$ in the dark, approximately $15 \%$ of p-HPA are adsorbed on the catalyst surface with and without BQ. However, when light is turned on, relatively no degradation can be observed in the presence of BQ. Degradation inhibition suggests that the adsorption on the catalyst surface and generation of reactive species such as $\mathrm{HO}_{2}{ }^{\bullet} / \mathrm{O}_{2}^{\bullet-}$, which are formed by dissolved oxygen with the generated electron in the valence band, are the main processes responsible for $p$-HPA degradation in the solution. At the same time, this figure indicated that the adsorbed $p$-HPA molecules are gradually degraded to some by-products. Possible implication of $\mathrm{H}_{2} \mathrm{PO}_{4}{ }^{-}$on hydroxyl radical quenching is negligible under adopted experimental conditions. As a matter of fact, considering the low second-order rate constant between $\mathrm{H}_{2} \mathrm{PO}_{4}{ }^{-}$and $\mathrm{HO}^{\bullet}$ in the solution $\left(\sim 2 \times 10^{4} \mathrm{M}^{-1} \mathrm{~s}^{-1}\right)$ [50] and concentration adopted for the desorption experiment $(2 \mathrm{mM})$, we can find that this reaction is few orders of magnitude lower than the reaction between $\mathrm{HO}^{\bullet}$ and $p$-HPA in the solution.

\subsection{Effect of dissolved oxygen}

Effect of dissolved oxygen on $p$-HPA degradation during the photocatalytic degradation process was investigated by supplying proper gases, that is, oxygen and nitrogen, to the reaction solutions $20 \mathrm{~min}$ before and during the experiments. Although no significant differences in the adsorption of pollutants on the catalyst are observed, $p$-HPA degradation is accelerated with the increase in oxygen concentration (Fig. 5). As a matter of fact, the pseudo-first-order degradation constant is increased 
from $(2.4 \pm 0.5) \times 10^{-3} \mathrm{~min}^{-1}$ in $\mathrm{N}_{2}$ saturated to $(2.4 \pm 0.2) \times 10^{-2} \mathrm{~min}^{-1}$ in $\mathrm{O}_{2}$ saturated solutions. This trend indicates that oxygen plays a key role in the photocatalytic degradation process mainly through the formation of $\mathrm{HO}_{2}{ }^{\bullet} / \mathrm{O}_{2}^{\bullet-}$ species.

\subsection{TOC removal efficiency and main intermediate product}

One of the most important parameters indicating complete mineralization of organic pollutants is TOC quantification. In addition to $p$-HPA degradation, mineralization is another important factor to estimate the removal ability of a catalyst. During irradiation, in the presence of $\mathrm{BiOCl}_{0.75} \mathrm{I}_{0.25}$ catalyst, the TOC changes $i$ ) in the solution and ii) after desorption, as shown in Fig. 6. TOC trend in the solution and after desorption of samples from the catalyst suggest that $p$-HPA and its by-products can be adsorbed on the catalyst surface.

These results also suggest that $\mathrm{BiOCl}_{0.75} \mathrm{I}_{0.25}$ catalyst can decompose by-products to $\mathrm{CO}_{2}$ and $\mathrm{H}_{2} \mathrm{O}$. After $2 \mathrm{~h}$ of irradiation, the TOC removal percentage is approximately $45 \%$ and is not significantly changed after $3 \mathrm{~h}$. This result suggests that some by-products can be still adsorbed on the catalyst surface, occupying the adsorption site. This result integrates the interfacial mechanism explained in section 3.4. However, after $5 \mathrm{~h}$ of irradiation, complete $p$-HPA degradation is observed. This result suggests that some by-products still adsorbed on the catalyst surface are not degraded. $\mathrm{HO}_{2}{ }^{\bullet} / \mathrm{O}_{2}{ }^{\bullet-}$ couple seems to be less reactive on the by-products than on 
p-HPA. $p$-HPA by-products that are generated during the photocatalytic process are detected by GC-MS after solvent extraction. 4-Hydroxybenzyl alcohol and $p$-hydroxybenzaldehyde are identified as main intermediates (Table S2) on the basis of molecular mass and data obtained from literature [28, 32].

\section{Conclusion}

The adsorption and photocatalytic degradation of $p$-HPA by $\mathrm{BiOCl}_{0.75} \mathrm{I}_{0.25}$ catalyst in water is investigated. Interfacial-mechanism experiments reveal that photocatalytic $p$-HPA degradation occurs mainly on the catalyst surface. $\mathrm{pH}$ strongly affects the adsorption percentage and degradation rate by changing the surface charge of catalyst and molecular form of $p$-HPA. The concentration of dissolved oxygen is a key parameter necessary to generate $\mathrm{HO}_{2}{ }^{\bullet} / \mathrm{O}_{2}{ }^{\bullet-}$, which is the main active species responsible for pollutant degradation. $\mathrm{BiOCl}_{0.75} \mathrm{I}_{0.25}$ catalyst shows promising $p$-HPA removal abilities. However, some photogenerated by-products that are still adsorbed on the catalyst surface seems to be not degraded. This photocatalyst that generates mainly $\mathrm{HO}_{2}{ }^{\bullet} / \mathrm{O}_{2}{ }^{\bullet-}$ is very promising. Indeed, this process can be applied and has strong implication in the treatment of polluted media, in which hydroxyl radical should be strongly scavenged by organic matter or inorganic constituents.

\section{Acknowledgements}

The authors gratefully acknowledge financial support from China Scholarship 
Council for Xiaoning Wang to study at the University Clermont Auvergne, France. This work was supported by the National Natural Science Foundation of China (NSFC 21077027), Shanghai Natural Science Fund (No. 12ZR1402000). Authors acknowledge financial support from the Region Council of Auvergne, from the "Féderation des Recherches en Environnement" through the CPER "Environment" founded by the Region Auvergne, the French government, FEDER from the European Community from PRC program CNRS/NSFC n ${ }^{\circ} 270437$ and from CAP $20-25$ I-site project. 


\section{References}

[1] S. Esplugas, J. Gimenez, S. Contreras, E. Pascual, M. Rodríguez, Comparison of different advanced oxidation processes for phenol degradation, Water Res., 36 (2002) 1034-1042.

[2] R. Andreozzi, V. Caprio, A. Insola, R. Marotta, Advanced oxidation processes (AOP) for water purification and recovery, Catal. Today, 53 (1999) 51-59.

[3] N. Oturan, E.D. Van Hullebusch, H. Zhang, L. Mazeas, H. Budzinski, K. Le Menach, M.A. Oturan, Occurrence and removal of organic micropollutants in landfill leachates treated by electrochemical advanced oxidation processes, Environ. Sci. Technol., 49 (2015) 12187-12196.

[4] M. Pera-Titus, V. Garcia-Molina, M.A. Baños, J. Giménez, S. Esplugas, Degradation of chlorophenols by means of advanced oxidation processes: a general review, Appl. Catal., B, 47 (2004) 219-256.

[5] E.J. Rosenfeldt, K.G. Linden, Degradation of endocrine disrupting chemicals bisphenol A, ethinyl estradiol, and estradiol during UV photolysis and advanced oxidation processes, Environ. Sci. Technol., 38 (2004) 5476-5483.

[6] M.M. Huber, S. Canonica, G.-Y. Park, U. Von Gunten, Oxidation of pharmaceuticals during ozonation and advanced oxidation processes, Environ. Sci. Technol., 37 (2003) 1016-1024.

[7] S.B. Abdelmelek, J. Greaves, K.P. Ishida, W.J. Cooper, W. Song, Removal of pharmaceutical and personal care products from reverse osmosis retentate using advanced oxidation processes, Environ. Sci. Technol., 45 (2011) 3665-3671.

[8] E. Neyens, J. Baeyens, A review of classic Fenton's peroxidation as an advanced oxidation technique, J. Hazard. Mater., 98 (2003) 33-50.

[9] W. Huang, M. Brigante, F. Wu, C. Mousty, K. Hanna, G. Mailhot, Assessment of the Fe (III)-EDDS complex in Fenton-like processes: from the radical formation to the degradation of bisphenol A, Environ. Sci. Technol., 47 (2013) 1952-1959.

[10] Y. Wu, M. Brigante, W. Dong, P. de Sainte-Claire, G. Mailhot, Toward a better understanding of Fe (III)-EDDS photochemistry: Theoretical stability calculation and experimental investigation of 4-tert-butylphenol degradation, J. Phys. Chem. A, 118 (2014) 396-403.

[11] Y. Wu, A. Bianco, M. Brigante, W. Dong, P. de Sainte-Claire, K. Hanna, G. Mailhot, Sulfate radical photogeneration using Fe-EDDS: Influence of critical parameters and naturally occurring scavengers, Environ. Sci. Technol., 49 (2015) 14343-14349.

[12] Y.A. Shaban, M.A. El Sayed, A.A. El Maradny, R.K. Al Farawati, M.I. Al Zobidi, Photocatalytic degradation of phenol in natural seawater using visible light active carbon modified (CM)-n- $\mathrm{TiO}_{2}$ nanoparticles under UV light and natural sunlight illuminations, Chemosphere, 91 (2013) 307-313.

[13] L. Zeng, W. Song, M. Li, D. Zeng, C. Xie, Catalytic oxidation of formaldehyde on surface of $\mathrm{HTiO}_{2} / \mathrm{HCTiO}_{2}$ without light illumination at room temperature, Appl. Catal., B, 147 (2014) 490-498.

[14] G. Yang, D. Chen, H. Ding, J. Feng, J.Z. Zhang, Y. Zhu, S. Hamid, D.W. Bahnemann, Well-designed 3D ZnIn $\mathrm{S}_{4}$ nanosheets/ $\mathrm{TiO}_{2}$ nanobelts as direct Z-scheme photocatalysts for $\mathrm{CO}_{2}$ 
photoreduction into renewable hydrocarbon fuel with high efficiency, Appl. Catal., B, 219 (2017) 611-618.

[15] D. Vildozo, R. Portela, C. Ferronato, J.-M. Chovelon, Photocatalytic oxidation of 2-propanol/toluene binary mixtures at indoor air concentration levels, Appl. Catal., B, 107 (2011) 347-354.

[16] D. Cazoir, L. Fine, C. Ferronato, J.M. Chovelon, Hydrocarbon removal from bilgewater by a combination of air-stripping and photocatalysis, J. Hazard. Mater., 235-236 (2012) 159-168.

[17] E. Moctezuma, E. Leyva, C.A. Aguilar, R.A. Luna, C. Montalvo, Photocatalytic degradation of paracetamol: Intermediates and total reaction mechanism, J. Hazard. Mater., 243 (2012) 130-138.

[18] X. Zhang, Z. Ai, F. Jia, L. Zhang, Generalized one-pot synthesis, characterization, and photocatalytic activity of hierarchical $\mathrm{BiOX}(\mathrm{X}=\mathrm{Cl}, \mathrm{Br}, \mathrm{I})$ nanoplate microspheres, J. Phys. Chem. C, 112 (2008) 747-753.

[19] P. Wang, Y. Wu, J. Shi, D. Liu, W. Dong, Preparation of carbon-supported Bi/Ti composites and its catalytic activity under solar irradiation, Appl. Surf. Sci., 292 (2014) 1077-1082.

[20] F. Dong, Y. Sun, M. Fu, Z. Wu, S. Lee, Room temperature synthesis and highly enhanced visible light photocatalytic activity of porous $\mathrm{BiOI} / \mathrm{BiOCl}$ composites nanoplates microflowers, J. Hazard. Mater., 219 (2012) 26-34.

[21] X. Xiao, R. Hao, M. Liang, X. Zuo, J. Nan, L. Li, W. Zhang, One-pot solvothermal synthesis of three-dimensional (3D) $\mathrm{BiOI} / \mathrm{BiOCl}$ composites with enhanced visible-light photocatalytic activities for the degradation of bisphenol-A, J. Hazard. Mater., 233 (2012) 122-130.

[22] X. Wang, Z. Zhang, Y. Xue, M. Nie, H. Li, W. Dong, Low crystallized $\mathrm{BiOCl}_{0.75} \mathrm{I}_{0.25}$ synthesized in mixed solvent and its photocatalytic properties under simulated solar irradiation, Mater. Lett., 136 (2014) 30-33.

[23] X. Wang, W. Bi, P. Zhai, X. Wang, H. Li, G. Mailhot, W. Dong, Adsorption and photocatalytic degradation of pharmaceuticals by $\mathrm{BiOCl}_{\mathrm{x}} \mathrm{I}_{\mathrm{y}}$ nanospheres in aqueous solution, Appl. Surf. Sci., 360 (2016) 240-251.

[24] T. Heberer, Occurrence, fate, and removal of pharmaceutical residues in the aquatic environment: a review of recent research data, Toxicol. Lett., 131 (2002) 5-17.

[25] S.J. Khan, J.E. Ongerth, Modelling of pharmaceutical residues in Australian sewage by quantities of use and fugacity calculations, Chemosphere, 54 (2004) 355-367.

[26] R. Andreozzi, V. Caprio, R. Marotta, D. Vogna, Paracetamol oxidation from aqueous solutions by means of ozonation and $\mathrm{H}_{2} \mathrm{O}_{2} / \mathrm{UV}$ system, Water Res., 37 (2003) 993-1004

[27] F.J. Benitez, J.L. Acero, F.J. Real, F.J. Rubio, A.I. Leal, The role of hydroxyl radicals for the decomposition of p-hydroxy phenylacetic acid in aqueous solutions, Water Res., 35 (2001) 1338-1343.

[28] M.A. Miranda, M.a.L. Marín, A.M. Amat, A. Arques, S. Seguí, Pyrylium salt-photosensitized degradation of phenolic contaminants present in olive oil wastewater with solar light: Part III. Tyrosol and p-hydroxyphenylacetic acid, Appl. Catal., B, 35 (2002) 167-174.

[29] I. Sanchez, F. Stüber, A. Fabregat, J. Font, A. Fortuny, C. Bengoa, Degradation of model olive 
mill contaminants of OMW catalysed by zero-valent iron enhanced with a chelant, J. Hazard. Mater., 199-200 (2012) 328-335.

[30] N. Flores, P.L. Cabot, F. Centellas, J.A. Garrido, R.M. Rodriguez, E. Brillas, I. Sires, 4-Hydroxyphenylacetic acid oxidation in sulfate and real olive oil mill wastewater by electrochemical advanced processes with a boron-doped diamond anode, J. Hazard. Mater., 321 (2017) 566-575.

[31] N. Flores, I. Sirés, R.M. Rodríguez, F. Centellas, P.L. Cabot, J.A. Garrido, E. Brillas, Removal of 4-hydroxyphenylacetic acid from aqueous medium by electrochemical oxidation with a BDD anode: Mineralization, kinetics and oxidation products, J. Electroanal. Chem., (2016).

[32] D.P. Minh, G. Aubert, P. Gallezot, M. Besson, Degradation of olive oil mill effluents by catalytic wet air oxidation: 2-Oxidation of p-hydroxyphenylacetic and p-hydroxybenzoic acids over Pt and Ru supported catalysts, Appl. Catal., B, 73 (2007) 236-246.

[33] D. Dulin, T. Mill, Development and evaluation of sunlight actinometers, Environ. Sci. Technol., 16 (1982) 815-820.

[34] F. Dong, Y. Sun, M. Fu, Z. Wu, S.C. Lee, Room temperature synthesis and highly enhanced visible light photocatalytic activity of porous $\mathrm{BiOI} / \mathrm{BiOCl}$ composites nanoplates microflowers, $\mathrm{J}$. Hazard. Mater., 219-220 (2012) 26-34.

[35] J. Xu, W. Meng, Y. Zhang, L. Li, C. Guo, Photocatalytic degradation of tetrabromobisphenol A by mesoporous BiOBr: Efficacy, products and pathway, Appl. Catal., B, 107 (2011) 355-362.

[36] C. Yang, F. Li, M. Zhang, T. Li, W. Cao, Preparation and first-principles study for electronic structures of $\mathrm{BiOI} / \mathrm{BiOCl}$ composites with highly improved photocatalytic and adsorption performances, J. Mol. Catal. A: Chem., 423 (2016) 1-11.

[37] L. Yu, X. Zhang, G. Li, Y. Cao, Y. Shao, D. Li, Highly efficient $\mathrm{Bi}_{2} \mathrm{O}_{2} \mathrm{CO}_{3} / \mathrm{BiOCl}$ photocatalyst based on heterojunction with enhanced dye-sensitization under visible light, Appl. Catal., B, 187 (2016) 301-309.

[38] X. Jia, J. Cao, H. Lin, M. Zhang, X. Guo, S. Chen, Transforming type-I to type-II heterostructure photocatalyst via energy band engineering: A case study of I-BiOCl/I-BiOBr, Appl. Catal., B, 204 (2017) 505-514.

[39] G.V. Buxton, C.L. Greenstock, W.P. Helman, A.B. Ross, Critical review of rate constants for reactions of hydrated electrons, hydrogen atoms and hydroxyl radicals $\left(\mathrm{OH} / \mathrm{O}^{-}\right)$in aqueous solution, J. Phys. Chem. Ref. Data, 17 (1988) 513-886.

[40] R. Palominos, J. Freer, M.A. Mondaca, H.D. Mansilla, Evidence for hole participation during the photocatalytic oxidation of the antibiotic flumequine, J. Photochem. Photobiol., A, 193 (2008) 139-145.

[41] C.L. Greenstock, G.W. Ruddock, Determination of superoxide $\left(\mathrm{O}_{2}{ }^{-}\right)$radical anion reaction rates using pulse radiolysis, International Journal for Radiation Physics and Chemistry, 8 (1976) 367-369.

[42] H. Lin, H. Ye, X. Li, J. Cao, S. Chen, Facile anion-exchange synthesis of BiOI/BiOBr composite with enhanced photoelectrochemical and photocatalytic properties, Ceram. Int., 40 (2014) 9743-9750. 
[43] X. Chang, M.A. Gondal, A.A. Al-Saadi, M.A. Ali, H. Shen, Q. Zhou, J. Zhang, M. Du, Y. Liu, G. Ji, Photodegradation of Rhodamine B over unexcited semiconductor compounds of $\mathrm{BiOCl}$ and BiOBr, J. Colloid Interface Sci., 377 (2012) 291-298.

[44] K. Li, Y. Liang, J. Yang, Q. Gao, Y. Zhu, S. Liu, R. Xu, X. Wu, Controllable synthesis of $\{001\}$ facet dependent foursquare $\mathrm{BiOCl}$ nanosheets: A high efficiency photocatalyst for degradation of methyl orange, J. Alloys Compd., 695 (2017) 238-249.

[45] G. Li, F. Qin, R. Wang, S. Xiao, H. Sun, R. Chen, BiOX (X=Cl, Br, I) nanostructures: mannitol-mediated microwave synthesis, visible light photocatalytic performance, and $\mathrm{Cr}(\mathrm{VI})$ removal capacity, J. Colloid Interface Sci., 409 (2013) 43-51.

[46] Y. Park, Y. Na, D. Pradhan, B.-K. Min, Y. Sohn, Adsorption and UV/Visible photocatalytic performance of $\mathrm{BiOI}$ for methyl orange, Rhodamine $\mathrm{B}$ and methylene blue: $\mathrm{Ag}$ and Ti-loading effects, CrystEngComm, 16 (2014) 3155.

[47] D. Zhang, J. Li, Q. Wang, Q. Wu, High $\{001\}$ facets dominated BiOBr lamellas: facile hydrolysis preparation and selective visible-light photocatalytic activity, J. Mater. Chem. A, 1 (2013) 8622.

[48] X. Gao, X. Zhang, Y. Wang, S. Peng, B. Yue, C. Fan, Photocatalytic degradation of carbamazepine using hierarchical $\mathrm{BiOCl}$ microspheres: Some key operating parameters, degradation intermediates and reaction pathway, Chem. Eng. J., 273 (2015) 156-165.

[49] J. Liang, C. Shan, X. Zhang, M. Tong, Bactericidal mechanism of BiOI-AgI under visible light irradiation, Chem. Eng. J., 279 (2015) 277-285.

[50] P. Maruthamuthu, P. Neta, Phosphate radicals. Spectra, acid-base equilibriums, and reactions with inorganic compounds, J. Phys. Chem., 82 (1978) 710-713. 
Table 1 Zeta potential of $\mathrm{BiOCl}_{0.75} \mathrm{I}_{0.25}$ catalyst, $p$-HPA molecule form and pseudo first-order reaction constant under different $\mathrm{pH}$

\begin{tabular}{cccc}
\hline $\mathbf{p H}$ & $\begin{array}{c}\text { Zeta } \\
\text { potential }\end{array}$ & $\boldsymbol{p}$-HPA & $\begin{array}{c}\text { Pseudo first-order reaction } \\
\text { constant }\left(\mathbf{m i n}^{-\mathbf{1}}\right)\end{array}$ \\
\hline 3.0 & $\approx-8 \mathrm{mV}$ & molecular form & $2.24 \times 10^{-2}$ \\
4.5 (natural $\mathrm{pH})$ & $\approx-21 \mathrm{mV}$ & $\begin{array}{c}50 / 50 \text { molecular and } \\
\text { anionic forms }\end{array}$ & $1.80 \times 10^{-2}$ \\
7.5 & $<-38 \mathrm{mV}$ & anionic form & $1.47 \times 10^{-2}$ \\
9.5 & $<-38 \mathrm{mV}$ & anionic form & $1.47 \times 10^{-2}$ \\
\hline
\end{tabular}




\section{Figures Caption}

Figure 1: XPS spectra of $\mathrm{BiOCl}_{0.75} \mathrm{I}_{0.25}$ sample: (A) survey spectra, (B) C 1s, (C) Bi 4f, (D) O 1s, (E) Cl 2p and (F) I 3d.

Figure 2: $p$-HPA concentration decrease with $(\circ)$ and without $(\bullet)$ BQ addition. Adsorption experiments were performed in the dark. Conditions: $[p-\mathrm{HPA}]=50 \mu \mathrm{M}$, $\left[\mathrm{BiOCl}_{0.75} \mathrm{I}_{0.25}\right]=0.3 \mathrm{~g} \mathrm{~L}^{-1},[\mathrm{BQ}]=2 \mathrm{mM}$ and $\mathrm{pH}=3.0$.

Figure 3: Time evolution of $p$-HPA concentration under dark and light experiments at different $\mathrm{pH}$ values. Conditions: $[p-\mathrm{HPA}]=50 \mu \mathrm{M},\left[\mathrm{BiOCl}_{0.75} \mathrm{I}_{0.25}\right]=0.3 \mathrm{~g} \mathrm{~L}^{-1}$.

Figure 4: (A) Effect of $\mathrm{NaH}_{2} \mathrm{PO}_{4}$ addition on the $p$-HPA adsorption (first $60 \mathrm{~min}$ in the dark) and on $p$-HPA concentration in solution after photocatalytic experiment. (B) $p$-HPA concentration in solution in the presence and absence of BQ before and after desorption experiments performed with $\mathrm{NaH}_{2} \mathrm{PO}_{4}$. Conditions: $[p$-HPA $]=50 \mu \mathrm{M}$, $\left[\mathrm{BiOCl}_{0.75} \mathrm{I}_{0.25}\right]=0.3 \mathrm{~g} \mathrm{~L}^{-1},[\mathrm{BQ}]=1 \mathrm{mM},\left[\mathrm{NaH}_{2} \mathrm{PO}_{4}\right]=2 \mathrm{mM}$ and $\mathrm{pH}=3.0$. Total $p$-HPA concentration $\left(p-\mathrm{HPA}_{\text {tot }}\right)$ corresponds to the sum of $p$-HPA in solution $\left(p-\mathrm{HPA}_{\mathrm{aq}}\right)+$ concentration of $p$-HPA adsorbed on the surface of the catalyst. 
Figure 5: (A) Effects of dissolved oxygen in the photocatalytic degradation of $p$-HPA by $\mathrm{BiOCl}_{0.75} \mathrm{I}_{0.25}$. Conditions: $[p-\mathrm{HPA}]=50 \mu \mathrm{M},\left[\mathrm{BiOCl}_{0.75} \mathrm{I}_{0.25}\right]=0.3 \mathrm{~g} \mathrm{~L}^{-1}, \mathrm{pH}=3.0$

Figure 6: TOC concentration in solution and total (in solution + adsorbed) as function of time. Irradiation starts after an equilibrium of $1 \mathrm{~h}$ in the dark. Conditions: [p-HPA] $=50 \mu \mathrm{M},\left[\mathrm{BiOCl}_{0.75} \mathrm{I}_{0.25}\right]=0.3 \mathrm{~g} \mathrm{~L}^{-1}$ and $\mathrm{pH}=3.0$. 

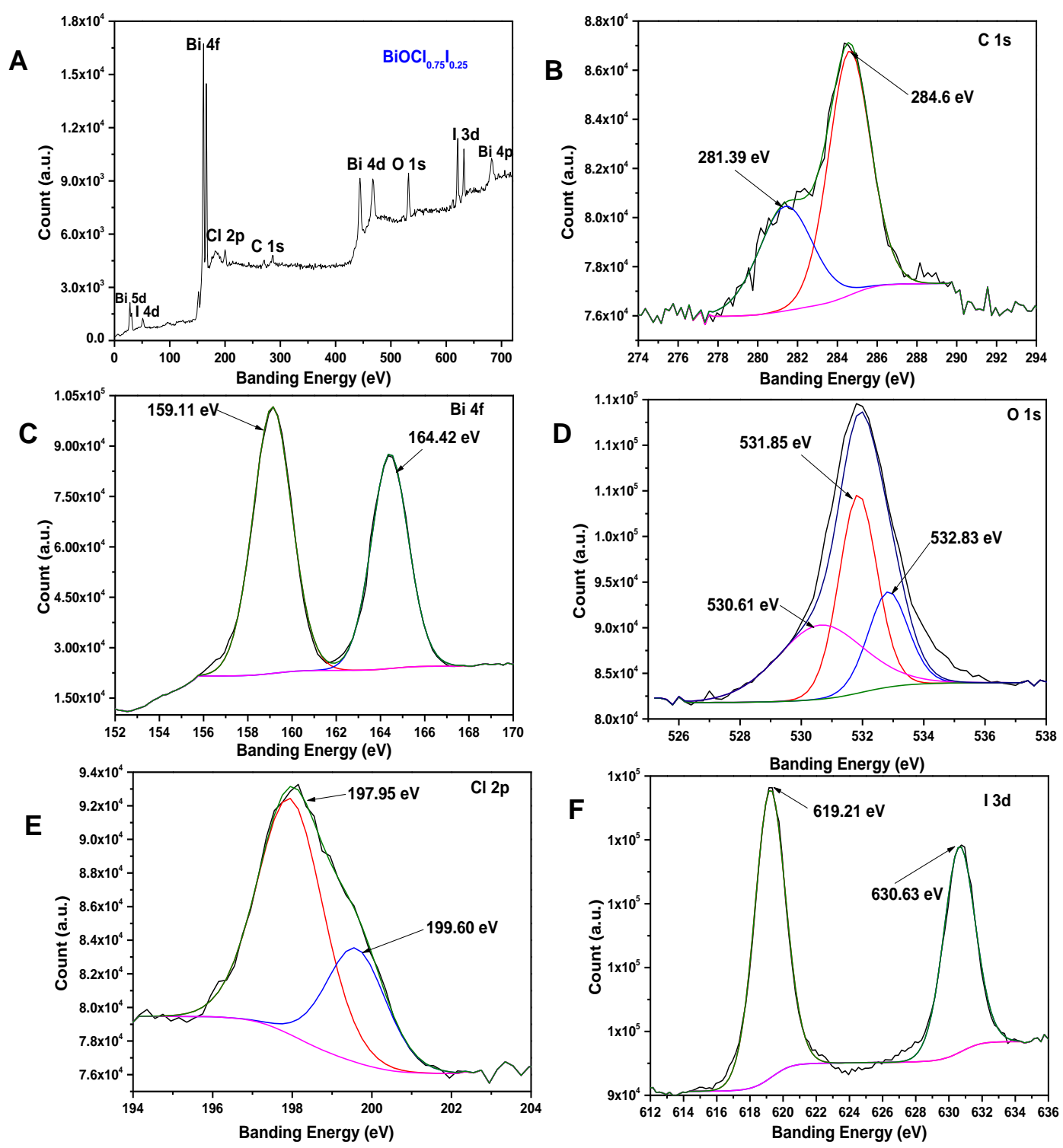

Figure 1 


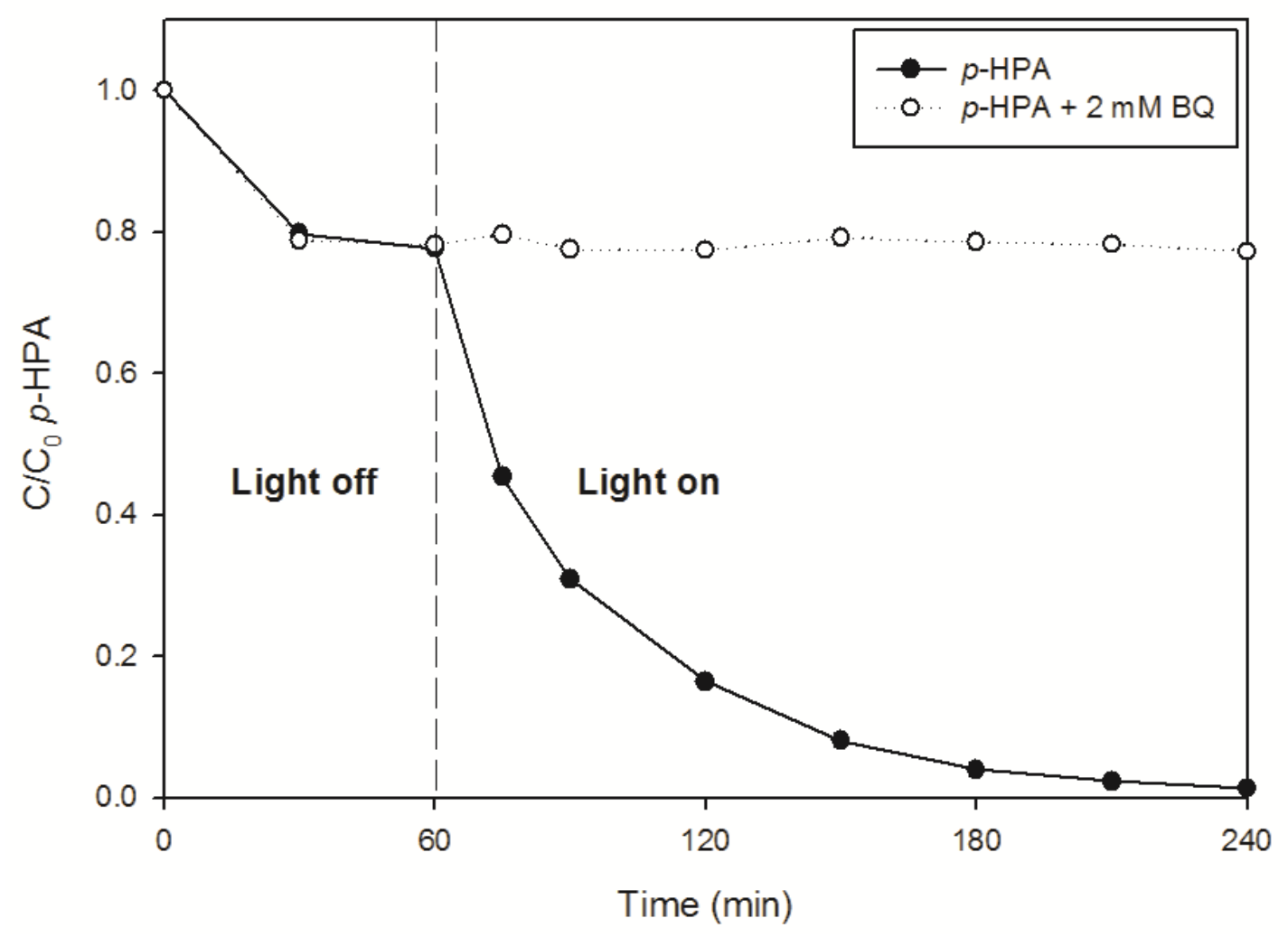

Figure 2 


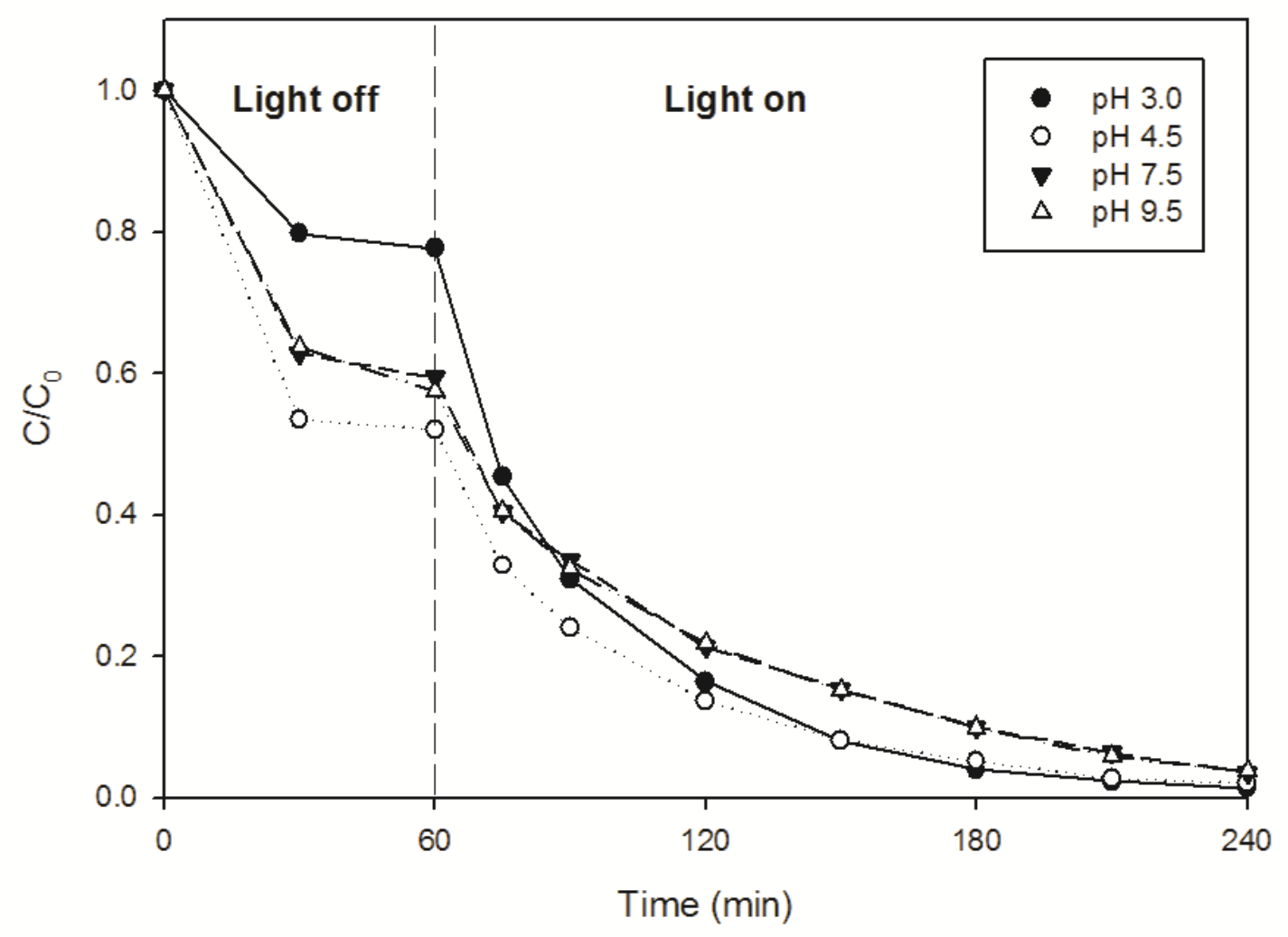

Figure 3 

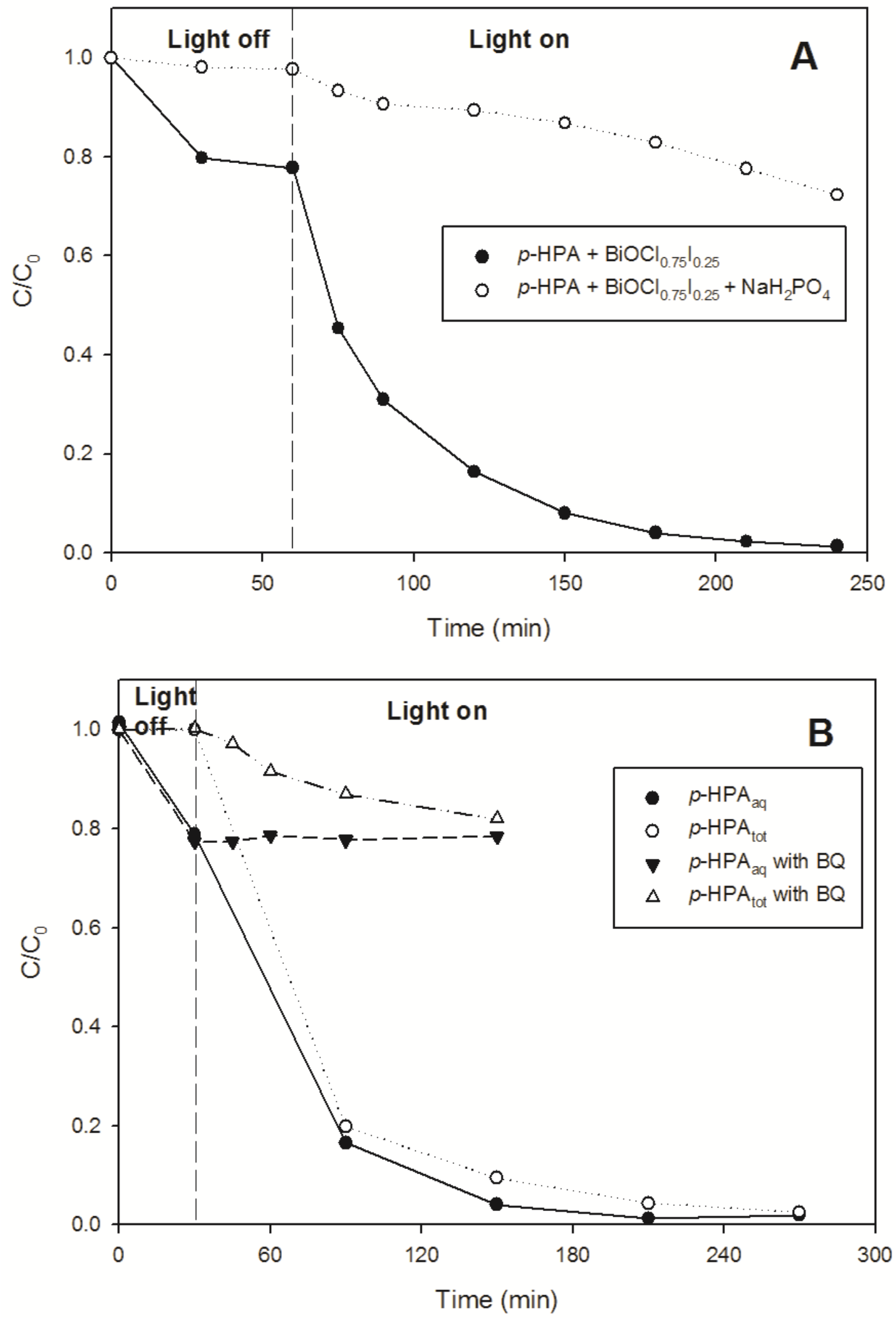

Figure 4 


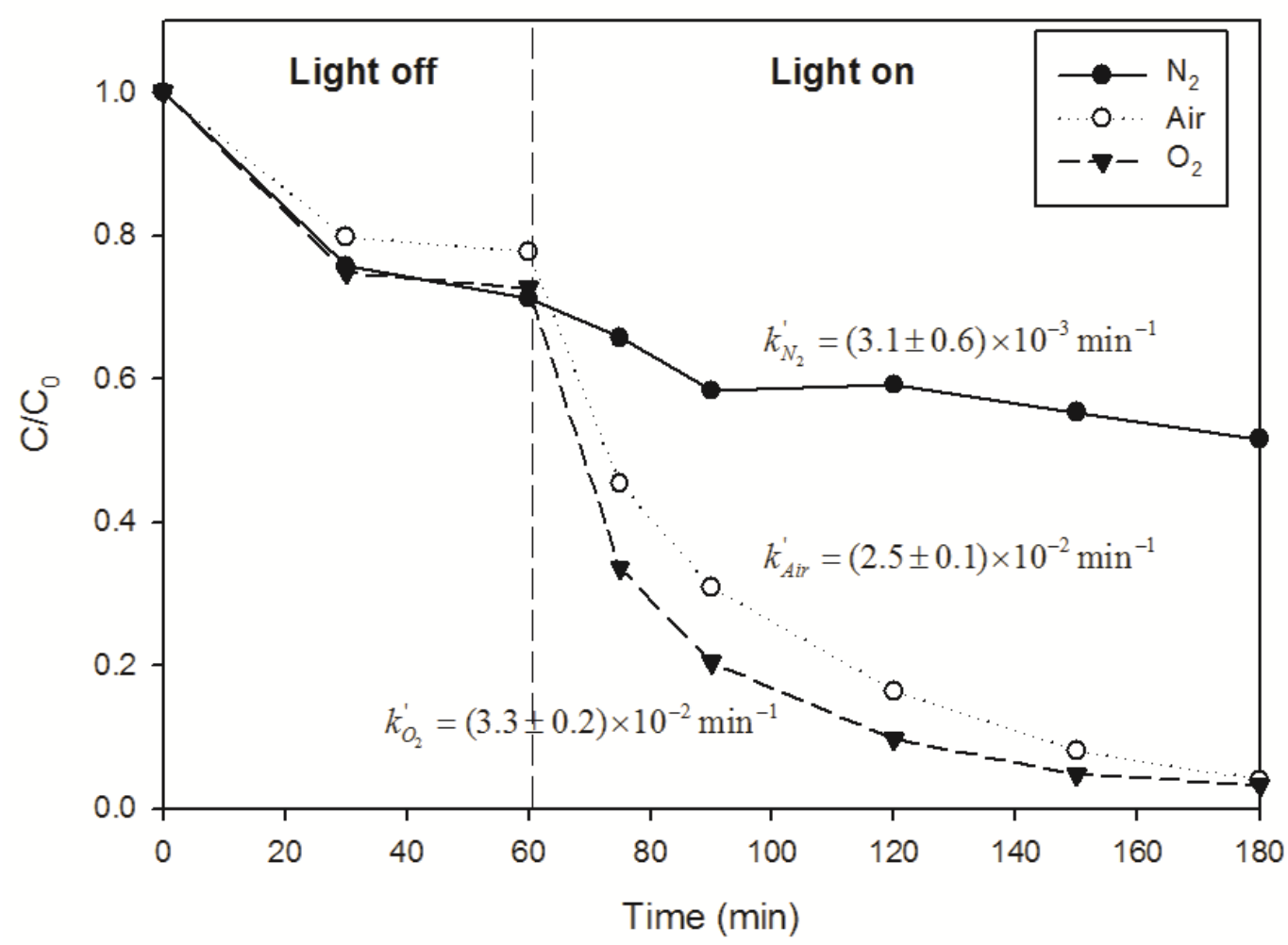

Figure 5 


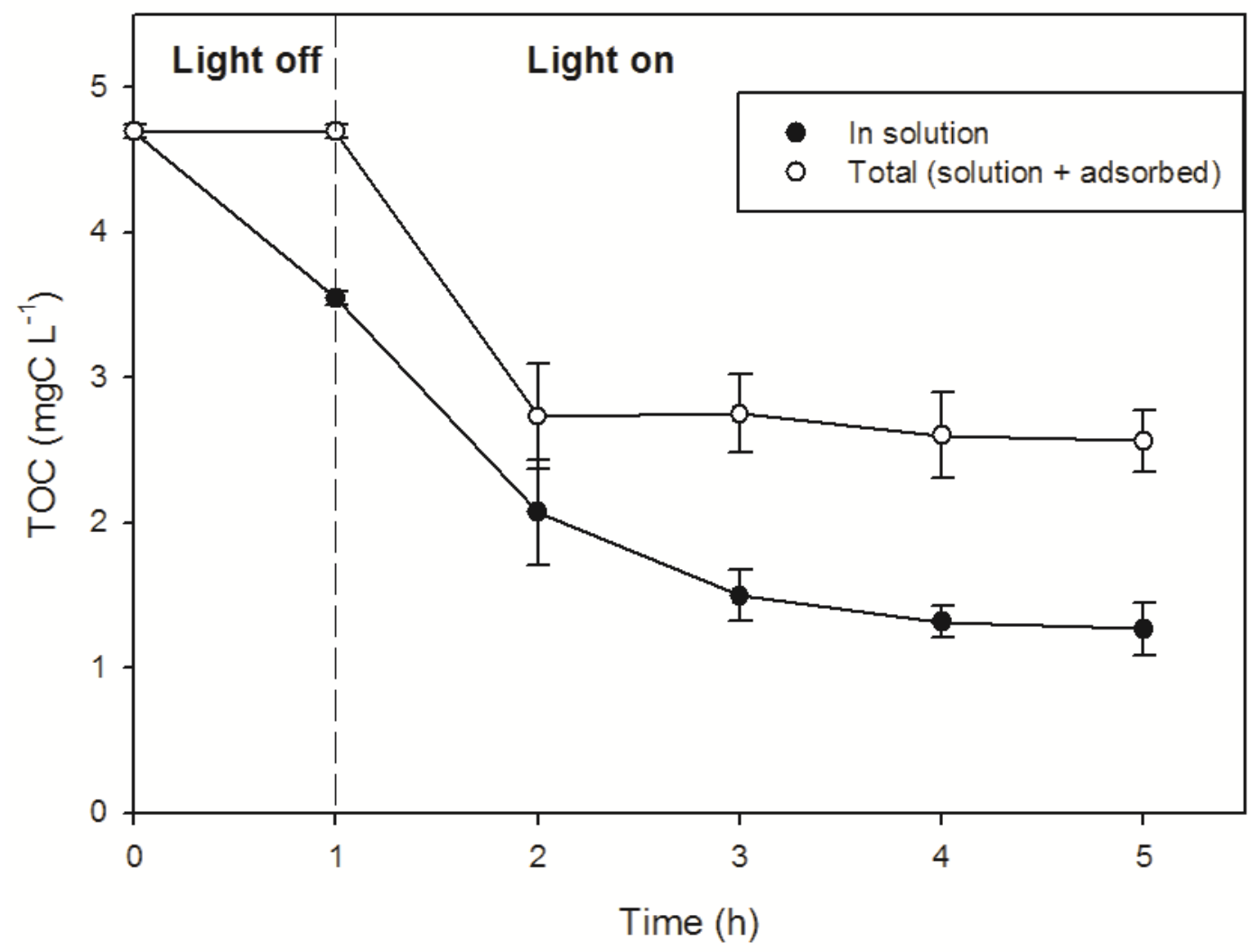

Figure 6 